\title{
Utilização efetiva e segura de filtros durante a ventilação mecânica em pacientes com COVID-19*
}

Effective and safe use of filters during mechanical ventilation in patients with COVID-19*

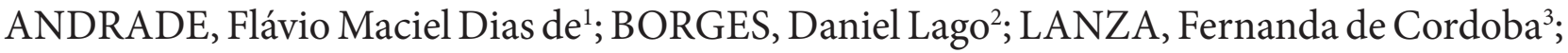
NOGUEIRA, Ingrid Correia ${ }^{4}$; em nome do Comitê COVID-19 da ASSOBRAFIR.
\end{abstract}

\section{Resumo}

Esse documento tem por objetivo apresentar recomendações para uso adequado e seguro de filtros de umidificação, aquecimento e/ou proteção nos ventiladores mecânicos em pacientes com COVID-19 suspeita ou confirmada. Utilizar adequadamente recursos para proteção das vias aéreas do paciente e minimizar a contaminação dos profissionais devem ser preocupações constantes em pacientes em uso de ventilação mecânica invasiva ou não invasiva. Para tanto é necessária a correta utilização de filtros de umidificação, aquecimento e/ou proteção. Os filtros trocadores de calor e umidade (HMEFs) são os preferencialmente utilizados, mas ressalta-se que na população neonatal há restrições devido a resistência e espaço morto impostos. Na indisponibilidade deste, a opção é utilizar o umidificador passivo, associado ao filtro barreira de alta eficiência (HEPA). A umidificação ativa/aquecida deve ser a de última escolha em adultos, mas é viável em neonatos, sendo necessário um HEPA no ramo expiratório.

Palavras-chave: Fisioterapia; umidificadores, filtros; COVID-19.

\footnotetext{
* Revisado por membros do Comitê COVID-19 da ASSOBRAFIR, nomeado por meio do memorando No 003/2020. Esta publicação é uma atualização da Comunicação Oficial "Utilização efetiva e segura de filtros durante a ventilação mecânica em pacientes com COVID-19”, chancelada pelo Comitê COVID-19 da ASSOBRAFIR, originalmente escrita pelos mesmos autores e divulgada em 11/05/2020 no endereço eletrônico https://assobrafir.com.br/wp-content/ uploads/2020/05/ASSOBRAFIR COVID-19 Filtros 2020.05.11.pdf.

${ }^{1}$ Universidade Católica de Pernambuco (UNICAP), Recife, Pernambuco, Brasil. Email: flaviomacielandrade@yahoo. com.br. FMDA - https://orcid.org/0000-0001-9571-6551

2 Hospital Universitário da Universidade Federal do Maranhão (HUUFMA), São Luís, Maranhão, Brasil. DLB - https://orcid.org/0000-0003-4082-527X

3 Universidade Federal de Minas Gerais (UFMG), Belo Horizonte, Minas Gerais, Brasil.

FCL - https://orcid.org/0000-0002-4748-6947

4 Centro Universitário Christus, Fortaleza, Ceará, Brasil. ICN - https://orcid.org/0000-0002-8711-817X
} 


\section{Abstract}

This document aims to provide recommendations for a correct and safe use of humidification, heating and/or protection filters in patients with suspected or confirmed COVID-19 on mechanical ventilation. An adequate use of resources for protecting the patients' airways and minimizing the risk of contamination by health professionals must be constant concerns when treating patients with COVID-19 on invasive or noninvasive mechanical ventilation. This requires the correct use of humidification, heating and/or protection filters. Heat and Moisture Exchange Filters (HMEF) should be preferred, however in preterm newborn babies there are restrictions due to the airway resistance and dead space imposed by this device. If there is no HMEF available, a passive humidifier is an alternative in combination with a High Efficiency Particulate Arrestance (HEPA) filter. Active/heated humidification should be the last option in adults, although it can be a feasible option in preterm newborn babies, but the use of a HEPA filter in the expiratory line is necessary.

Keywords: Physiotherapy; humidifiers; filters; COVID-19.

\section{Objetivo}

O objetivo do presente documento é apresentar recomendações para uso adequado e seguro de filtros de umidificação, aquecimento e/ou proteção nos ventiladores mecânicos em pacientes com COVID-19, ou naqueles que estejam em investigação da doença.

\section{Contextualização}

A pandemia causada pelo vírus SARS-CoV-2, que teve início em dezembro de 2019 na China, aumentou de maneira importante o volume de internações de pacientes nas unidades de terapia intensiva $(\mathrm{UTI})^{1}$. Diante dessa perspectiva, o manejo da ventilação mecânica (VM) invasiva no tratamento da insuficiência respiratória aguda (IRpA) causada pela COVID-19 é importante, e foi robustamente descrito ${ }^{2}$. Adicionalmente, há necessidade da utilização de maneira apropriada de recursos para minimizar a contaminação dos profissionais que atuam frente a esses pacientes. A utilização de equipamentos de proteção individual (EPIs), previamente descrita em documento da ASSOBRAFIR, é uma das estratégias de prevenção ${ }^{3}$. Ademais, minimizar a eliminação de aerossóis durante o uso da VM é de extrema importância. Para tanto, a correta utilização de filtros é fundamental para evitar a disseminação viral por intermédio dos ventiladores mecânicos.

Em pacientes sob VM, a umidificação passiva é uma possível estratégia para aquecer e umidificar o gás inalado (trocadores de calor e umidade, do inglês heat and moisture exchanger HME). Quando estes dispositivos possuem uma barreira hidrostática, podem ainda filtrar o gás exalado, evitando a dispersão de aerossol contaminado (filtros trocadores de calor e umidade, do inglês heat and moisture exchanger filter - HMEF). Os umidificadores passivos têm como base a troca de calor e umidade, utilizando um princípio higroscópico (utilizam condensador de baixa condutividade térmica como papel) e/ou hidrofóbico (utilizam elemento que repele a água, com grande superfície e baixa condutividade $)^{4-6}$.

Outra possibilidade para filtração do gás exalado é o filtro HEPA (do inglês high efficiency particulate air - alta eficiência de filtração de partículas). Na figura 1 são apresentadas a descrição e modelos de umidificadores passivos e filtros HEPA. 
Figura 1 | Descrição dos principais tipos de umidificadores/filtros passivos utilizados na ventilação mecânica, bem como, respectivas imagens. No rótulo da embalagem de cada filtro está descrita a característica e seu enquadramento nas categorias citadas.
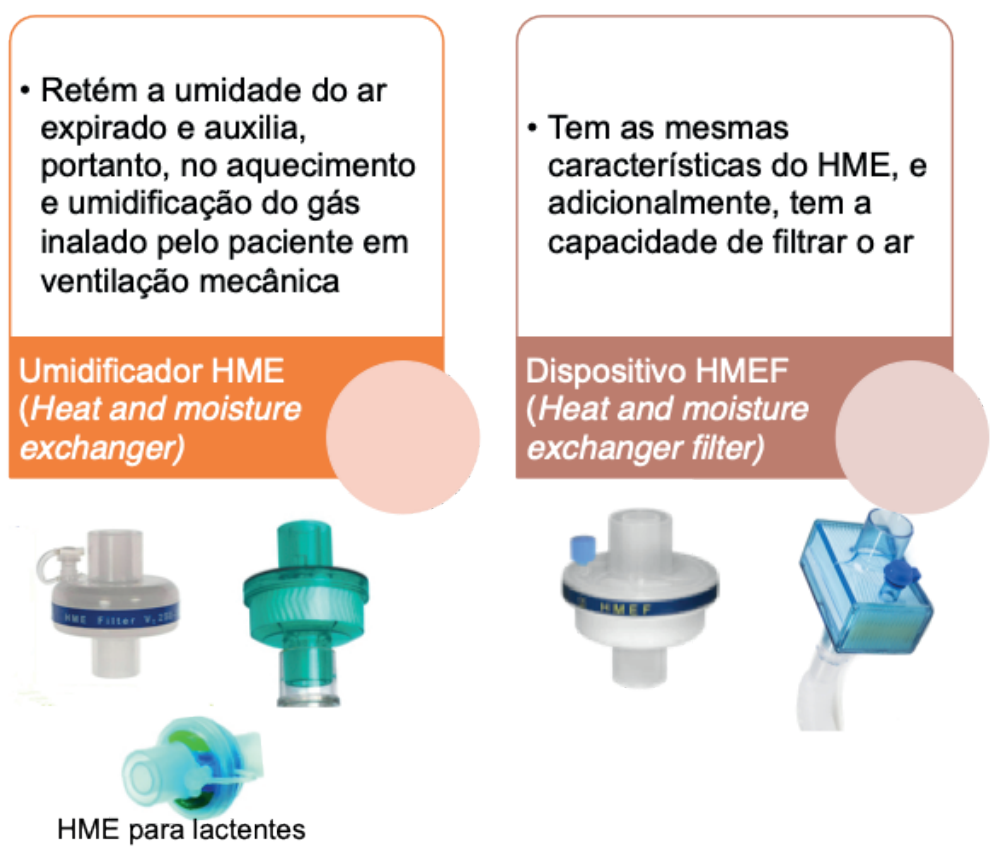

- Tem alta eficiência na filtragem de partículas aéreas, tanto bactérias quanto vírus.

- Os ideais são aqueles que filtram acima de $99,97 \%$.

\section{Filtro HEPA (High} Efficiency Particulate Air)

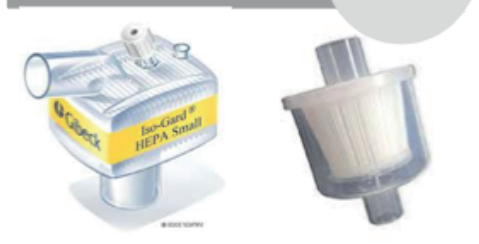

Fonte: arquivos dos autores.

\section{Emprego da umidificação passiva na VM invasiva}

Os umidificadores passivos são instalados logo após o "Y" do circuito do ventilador mecânico. Preferência deve ser dada ao uso do HMEF, pois reúne as funções de filtração, aquecimento e umidificação o gás. É importante ressaltar que o HMEF precisa ter eficiência de filtração bacteriana e viral maior que $99,99 \%$ e poro mínimo de $2 \mu \mathrm{m}$ para ser empregado com segurança durante a VM aplicada aos casos suspeitos ou confirmados da COVID-19,6. Entretanto, na impossibilidade de usálos, os dispositivos HME são a opção, devendo ser instalados na mesma localização, associados ao filtro HEPA posicionado na saída do ramo expiratório, favorecendo a filtração do gás expirado antes da sua eliminação para o ambiente (Figura 2). 
Figura 2 | Ilustração da localização do HMEF (heat and moisture exchanger filter), HME (heat and moisture exchanger) e HEPA (high efficiency particulate air) durante a ventilação mecânica invasiva. Em (A), HMEF após o Y; Em (B), filtro HME após o Y, associado ao HEPA no ramo expiratório.

\section{A}

\section{VENTILADOR}

\section{MECÂNICO}

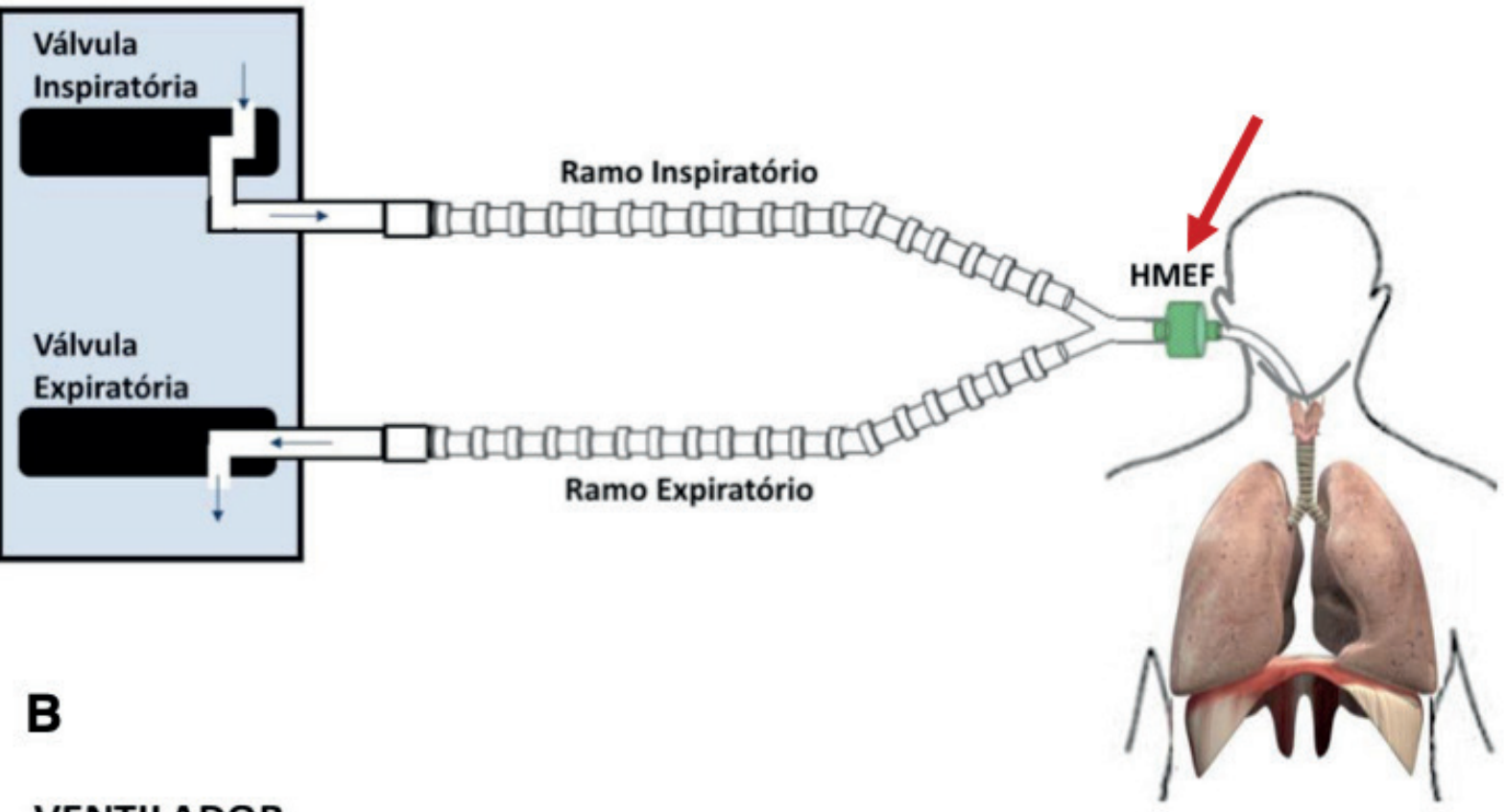

\section{VENTILADOR}

MECÂNICO

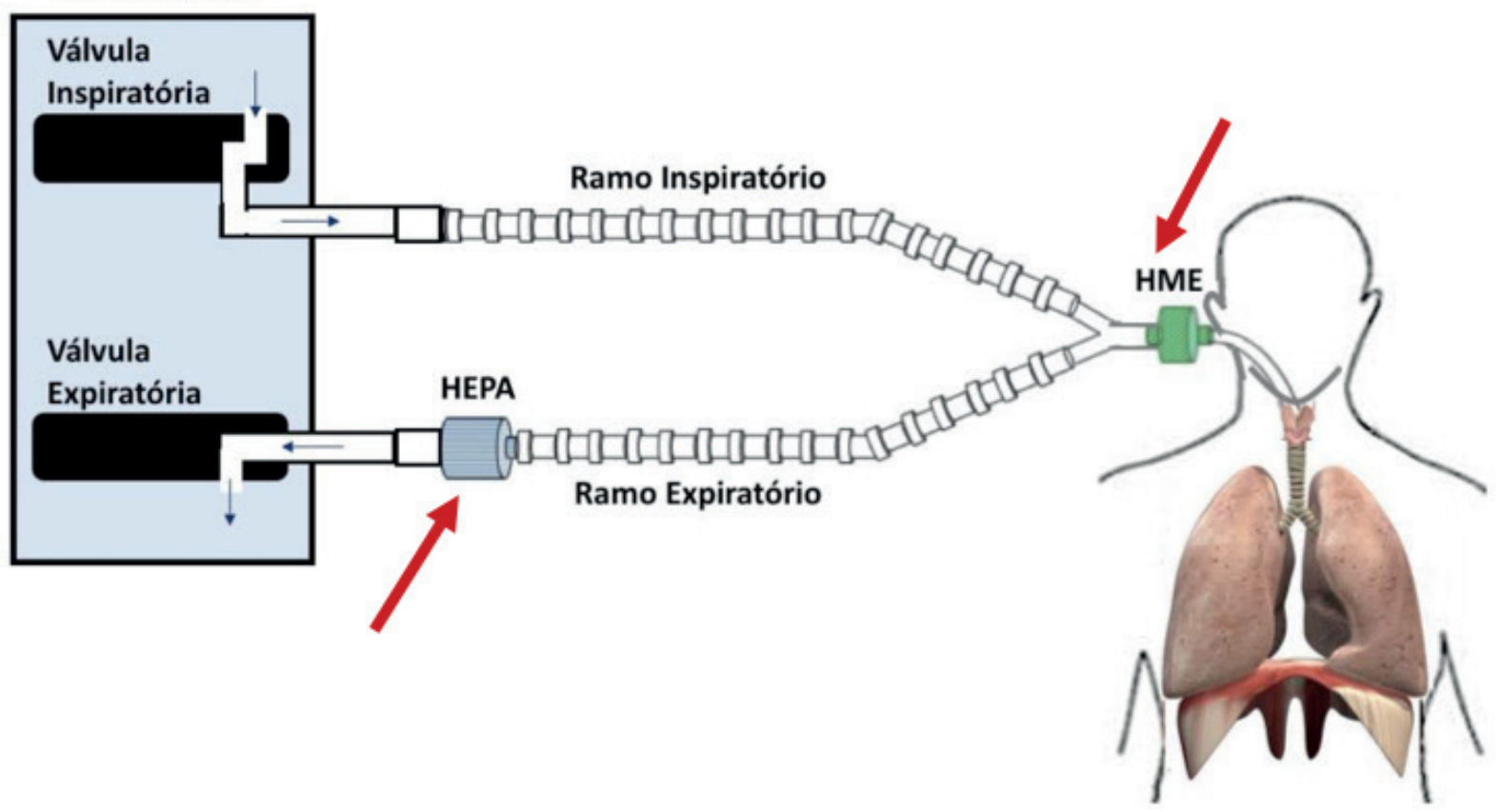

Fonte: arquivos dos autores. 
Por vezes, erros são cometidos durante a utilização destes dispositivos. A tabela 1 apresenta situações que não são recomendadas durante o emprego do HMEF, HME e HEPA.

Existem algumas particularidades em relação ao uso destes dispositivos na população pediátrica, as quais estão expostas na tabela $2^{6}$.

Tabela 1 | Descrição do que não é recomendado em relação ao emprego do HMEF (heat and moisture exchanger filter), HME (heat and moisture exchanger) e HEPA (high efficiency particulate air) durante a ventilação mecânica.

\section{Não é recomendado}

- Emprego simultâneo de HMEF e filtro HEPA (eleva o custo e produz aumento da resistência ao fluxo aéreo).

- Uso de HME ou HMEF próximo à válvula expiratória (aumenta o risco de condensação no cassete expiratório).

- Uso de filtro HEPA ou HMEF na saída do ramo inspiratório do circuito, caso se utilize fontes canalizadas de gases e se a manutenção preventiva com troca dos filtros internos ocorrer com regularidade.

Tabela 2 Particularidades em relação ao uso dos umidificadores passivos e filtros durante a ventilação mecânica invasiva na população pediátrica.

\section{Atenção aos pacientes pediátricos}

- Há umidificadores passivos (Heat and moisture exchanger - HME) para diversas idades e pesos, na população infantil.

- Avaliar no manual do dispositivo (HME ou HMEF), o tamanho do espaço morto, resistência imposta pelo fluxo, e a capacidade de umidificação.

- Alguns dispositivos Heat and moisture exchanger filter (HMEF) e HME, NÃO têm capacidade de atender o baixo volume corrente de pacientes neonatos, em especial aquels abaixo de $1500 \mathrm{gr}$.

- O fisioterapeuta deve estar atento ao uso desses dispositivos na população infantil (verificar volume de espaço morto e resistência oferecida antes de instalar no paciente). 


\section{Desconexão do paciente da ventilação mecânica}

Sugere-se, diante da necessidade de desconectar o paciente da VM para a troca de filtro ou outros procedimentos, a seguinte sequência para evitar dispersão de aerossol contendo vírus (Tabela 3):

Tabela 3 | Sequência segura para desconectar o paciente do ventilador mecânico e evitar dispersão de aerossóis.

\section{Sequência:}

1. Coloque o ventilador mecânico em stand by, ou desligue-o;

2. Rapidamente, clampleie o tubo orotraqueal (TOT) e realize a desconexão do circuito

3. Faça a função necessária (troca de filtros, ou do circuito de aspiração);

4. Reconectar o ventilador mecânico no TOT, desclampleie o TOT e volte o VM;

5. Ligue o ventilador mecânico, ou retire do modo stand by.

\section{Emprego da umidificação passiva na ventilação mecânica não invasiva}

A utilização da ventilação mecânica não invasiva (VNI) em pacientes com COVID-19 é alvo de muita controvérsia ${ }^{1,8,9}$. Entretanto, caso opte-se por sua utilização, os mesmos cuidados quanto ao risco de dispersão de aerossóis são necessários. Embora não indicados, caso seja necessário utilizar ventiladores específicos para VNI com circuito único (situação possível em casos de colapso do sistema de saúde com falta de ventiladores com circuitos duplos), o dispositivo HMEF deve ser escolhido, sendo colocado na saída da interface, antes do orifício de exalação do circuito (Figura 3).

Utilizando-se o ventilador mecânico convencional com circuito duplo (ramo inspiratório e expiratório separados) no modo para VNI, o mesmo padrão de uso de filtros e dispositivos de umidificação passiva descritos para VM invasiva é utilizado. 
Figura 3 | Ilustração da localização do HMEF (heat and moisture exchanger filter), HME (heat and moisture exchanger) e HEPA (high efficiency particulate air) durante a ventilação mecânica não invasiva com circuito duplo. Em (A), filtro HMEF após o Y; em (B), HME após o Y, associado ao HEPA no ramo expiratório.
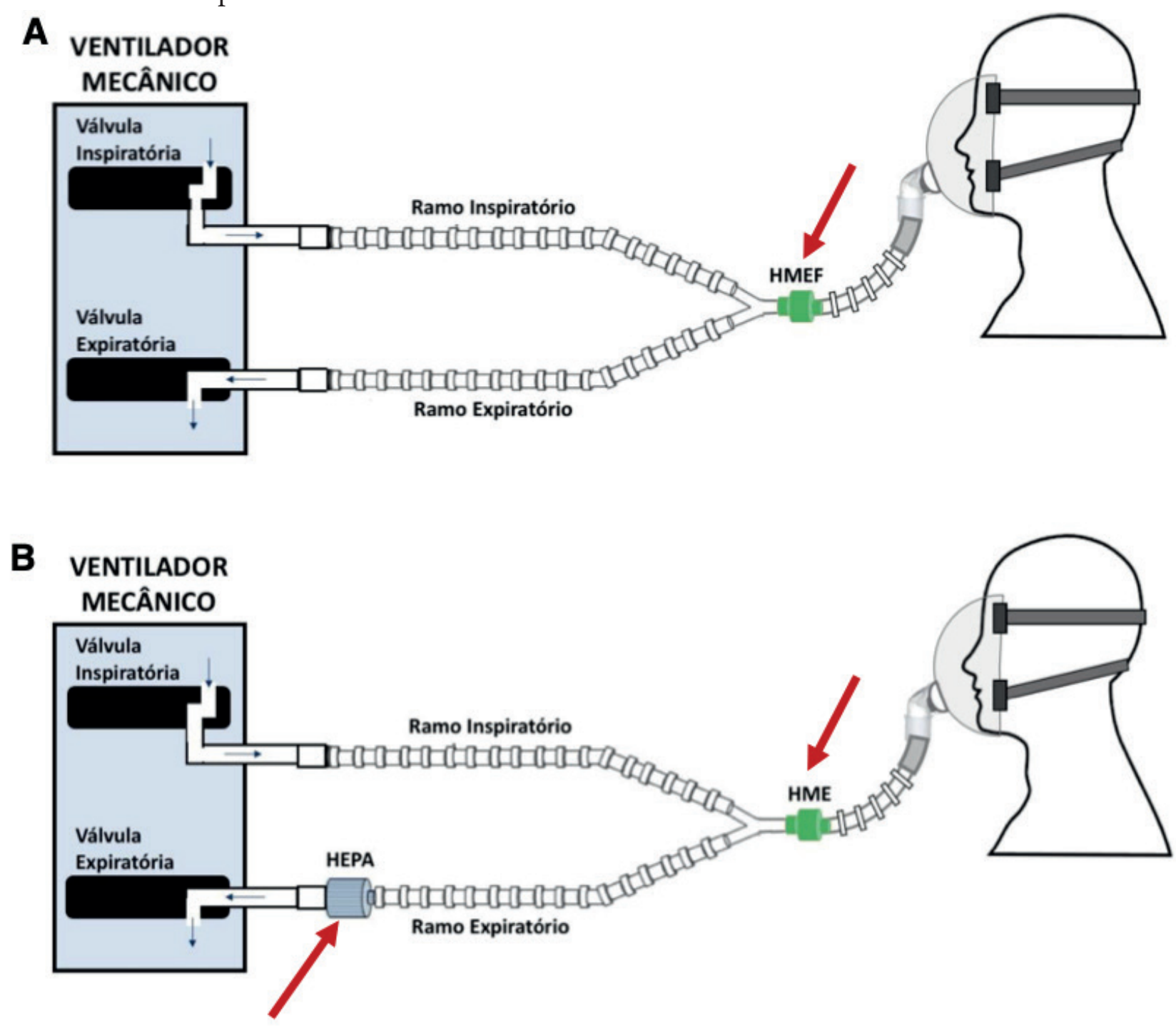

Fonte: arquivos dos autores.

\section{Umidificação ativa na ventilação mecânica invasiva ou não invasiva}

A umidificação ativa (umidificadores aquosos aquecidos) deve ser evitada em pacientes com COVID-19. Esse tipo de umidificação aumenta a chance de dispersão de gotículas para o ambiente, favorecendo a disseminação do vírus ${ }^{6}$.

Em pacientes neonatos, em especial nos recém nascidos prematuros, a umidificação ativa é preferida, pois os dispositivos HME e HMEF apresentam espaço morto e resistência inadequados para esta população, promovendo ineficiência na umidificação e aquecimento; aumento do trabalho muscular ventilatório; e alteração da troca gasosa. Durante o emprego da umidificação ativa, o uso do filtro HEPA no ramo expiratório é mandatório, para limitar a eliminação de vírus para o ambiente (Figura 4). 
Figura 4 | Ilustração da localização do umidificador ativo e do filtro HEPA na ventilação mecânica invasiva.

\section{VENTILADOR MECÂNICO}

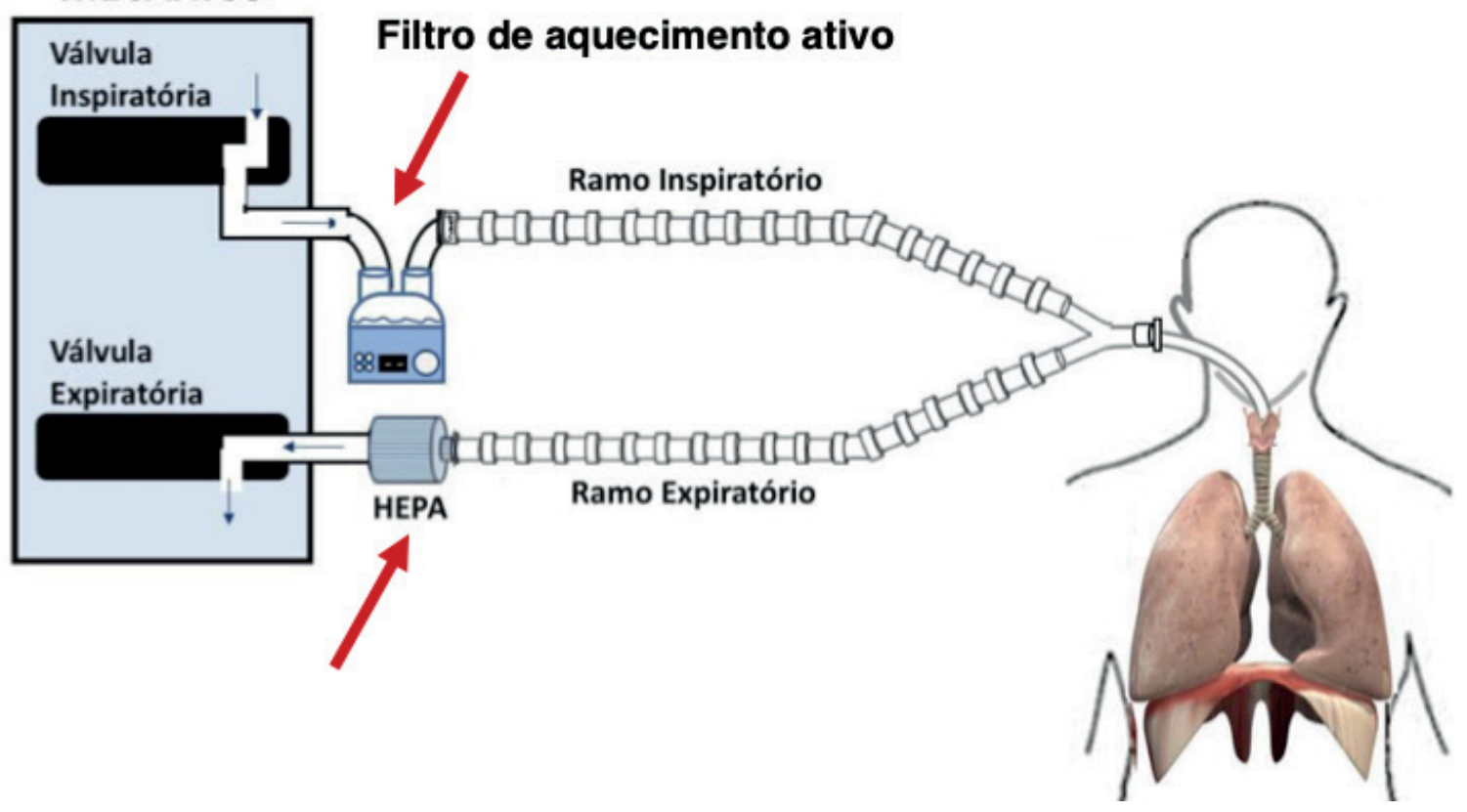

Fonte: arquivos dos autores.

Os dispositivos HME e HMEF não devem ser utilizados em associação com os umidificadores ativos.

\section{Considerações Finais}

Os sistemas passivos de umidificação e aquecimento são os recomendados para os pacientes sob VM pela COVID-19. Adicionalmente, a filtração do ar exalado é de extrema importância para reduzir a chance de contaminação dos profissionais que atuam nas UTI.

O HMEF deve ser preferencialmente utilizado, mas ressalta-se que na população neonatal há restrições devido a resistência e espaço morto impostos. Na indisponibilidade do filtro HMEF, a opção é utilizar o HME associado ao HEPA. A umidificação ativa/aquecida deve ser a de última escolha em adultos, mas é viável em neonatos. Havendo necessidade de usá-la, a presença do filtro HEPA no ramo expiratório é imprescindível.

\section{Referências}

1. CDC. Coronavirus disease 2019 (COVID-19): situation summary [Internet]. Atlanta: Centers for Disease Control and Prevention; 2019. Available from: https://www.cdc.gov/ coronavirus/2019ncov/summary.html.

2. Martinez BP, Andrade FMD, Roncalli A, Martins JA, Cavalheiro LV, Matte DL, et al. Indicação e uso da ventilação não-invasiva e da cânula nasal de alto fluxo, e orientações sobre manejo da ventilação mecânica invasiva no tratamento da insuficência respiratória aguda na COVID-19 [Internet]. São 
Paulo: ASSOBRAFIR; 2020. Available from: https://assobrafir.com.br/wp-content/uploads/2020/03/ ASSOBRAFIR COVID-19 VNI.pdf.

3. Matte DL, Andrade FMD, Martins JA, Martinez BP, Karsten M. O fisioterapeuta e sua relação com o novo betacoronavirus 2019 (2019-nCoV): comunicação oficial da ASSOBRAFIR [Internet]. São Paulo: ASSOBRAFIR; 2020. Available from: https://assobrafir.com.br/assobrafir betacoronavirus2019/2020.

4. McNamara DG1, Asher MI, Rubin BK, Stewart A, Byrnes CA. Heated humidification improves clinical outcomes, compared to a heat and moisture exchanger in children with tracheostomies. Respir Care. 2014 Jan;59(1):46-53. doi: 10.4187/respcare.02214. Epub 2013 Jun 13.

5. Lee JE, Kim JH, Kim S-O. Misinterpretation of carbon dioxide monitoring because of deadspace of heat and moisture exchanger with a filter in pediatric anesthesia: A case report. Medicine (Baltimore). 2018 Aug;97(35):e12158. doi: 10.1097/MD.0000000000012158.

6. Guia Sociedad Chilena de Medicina Intensivista. Guía de Reomendaciones de Armado y Uso de Filtros em Ventilación Mecánica COVID19 [Internet]. Santiago: Sociedad Chilena de Medicina Intensivista; [2020]. Available from: https://www.medicina-intensiva.cl/site/covid/armado filtros. pdf

7. Kelly M, Gillies D, Todd DA, Lockwood C. Heated humidification versus heat and moisture exchangers for ventilated adults and children. Cochrane Database Syst Rev. 2010 Apr 14;(4):CD004711. doi: 10.1002/14651858.CD004711.pub2.

8. ASSOBRAFIR. Comunicação Oficial COVID-19. Intervenção na Insuficiência Respiratória Aguda [Internet]. São Paulo: Associação Brasileira de Fisioterapia Cardiorrespiratória e Fisioterapia em Terapia Intensiva; 2020. Available from: https://assobrafir.com.br/covid-19 vni/

9. ASSOBRAFIR. Comunicação Oficial COVID-19. Indicação e uso da ventilação não-invasiva e da cânula nasal de alto fluxo, e orientações sobre manejo da ventilação mecânica invasiva no tratamento da insuficência respiratória aguda na covid-19 [Internet]. São Paulo: Associação Brasileira de Fisioterapia Cardiorrespiratória e Fisioterapia em Terapia Intensiva; 2020. Available from: https:// assobrafir.com.br/wp-content/uploads/2020/03/ASSOBRAFIR_COVID-19 VNI.pdf.

Submissão em: 05/06/2020

Aceite em: 15/07/2020 